\title{
Blood pressure and its correlates in an African tribe in urban and rural environments
}

\author{
N POULTER, ${ }^{12} \mathrm{~K}$ T KHAW, ${ }^{1}$ B E C HOPWOOD,${ }^{2}$ M MUGAMBI, ${ }^{3}$ W S PEART, ${ }^{1}$ G \\ ROSE, ${ }^{4}$ AND P S SEVER \\ From the Departments of Medicine, ${ }^{1}$ and Clinical Pharmacology, ${ }^{5}$ St Mary's Hospital Medical School, London \\ W2, UK, Wellcome Trust Research Laboratories, W PO Box 43640, Nairobi, Kenya. Clinical Research Centre, ${ }^{3}$ \\ Kenyan Medical Research Institute, Nairobi, Kenya, and London School of Hygiene and Tropical Medicine, \\ London WC1E 7HT, UK
}

SUMMARY As part of a longitudinal study of migrants who move from a subsistence farming rural society to Nairobi, blood pressures and associated factors were measured in cross sectional studies of members of the Luo tribe in their traditional rural environment and in the urban environment of Nairobi. Blood pressures in Nairobi correlated with duration of urban residence. In the rural area men showed a negligible rise in blood pressure with age, and both sexes showed a significantly smaller rise than in the urban area. Although mean weights of the rural group were smaller, this did not account for all the urban/rural differences in blood pressures. Nevertheless, mean urinary sodium concentration and sodium ratios (sodium/potassium and sodium/creatinine) were significantly higher in the urban group whereas mean urinary potassium concentration and potassium/creatinine ratio were significantly lower. Perhaps the ratio of sodium to potassium in the diet contributes to the different blood pressure profiles of these two populations.

\begin{abstract}
Despite several studies of "low blood pressure populations" in Africa, ${ }^{1-7}$ virtually no data on their sodium intake have been reported. It has been suggested that some of these populations have a low salt intake, ${ }^{78}$ but only one study ${ }^{7}$ provides substantial data to support this theory. We are carrying out a longitudinal study of the blood pressures of migrants who leave a rural community in west Kenya to live in the urban environment of Nairobi. The results are presented here of the baseline studies of blood pressure patterns in the rural and urban environments, including data on urinary electrolyte excretion.
\end{abstract}

\section{Methods}

During 1980 a population census was carried out in 22 villages in Siaya District, Nyanza Province, Kenya. These villages are inhabited by about 15000 people of the Luo tribe, a nilo-hamitic group whose major occupation is subsistence farming. Using this census, 861 men and women aged 20 and over were selected by random sampling of households. We identified 310 Luo who originated from this rural area but who were resident at that time in Nairobi by contact tracing, using addresses obtained in the rural area and in Nairobi.

Both groups of subjects were studied in their homes. A standard questionnaire was administered by trained Luo fieldworkers. Blood pressure was then measured twice using a Hawkesley random zero sphygmomanometer ${ }^{9}$ after the subject had been lying down for five minutes. Observers had been trained and standardised in blood pressure measurement, ${ }^{10}$ and diastolic pressure was recorded at phase 5. Heart rate was recorded between blood pressure readings and the mean of the two blood pressure readings was used for analysis. Weight, height, and triceps skinfold thicknesses were measured using standard techniques. ${ }^{11}$ The mean of two skinfold measurements was used for analysis. Finally, a casual urine sample was collected and the time and ambient temperature were recorded.

\section{Results}

Of those selected and still resident in the rural area, $98 \%$ were studied. All of those traced in Nairobi were included in the urban study. Tables 1 and 2 show that 
mean blood pressures are similar in the rural and urban groups until the age of 35 . This is true for both sexes. Numbers of older women in the urban group are small owing to selective migration; therefore it is unwarranted to draw conclusions on rural urban differences in the older age range in women. Blood pressures correlate significantly with age in both urban and rural groups. For men, the linear regression slopes differ significantly for the rural and urban Luo, the latter showing a greater rise with age (table 1). In the rural area blood pressure rises much less with age in men than women (table 2), but in the town this sex difference disappears. The rise of diastolic pressure with age in the rural men is inconsistent and negligible, and systolic only rises over the age of 65 . In contrast, among rural women both systolic and diastolic pressure rises with age and this rise is apparently less than in urban women, although numbers in the latter case are small. Results for men and women combined are shown in the figure.

\section{WEIGHT AND BODY BUILD}

Tables 3 and 4 show the mean weight, body mass index $\left(\mathrm{wt} / \mathrm{ht}^{2}\right)$, and triceps skinfold thickness by age and sex in the two populations. Mean weights of the rural Luo decreased with age $(r=-0.24 ; p<0.001)$ whereas in the urban Luo they increased $(r=+0 \cdot 18$; $\mathrm{p}<0.001)$. Weight correlated significantly with blood pressure in the rural group but only after controlling for the effect of age. In the urban group systolic and diastolic pressures correlated with weight

Table 1 Mean blood pressure by age in men

\begin{tabular}{|c|c|c|c|c|c|c|c|}
\hline \multirow[b]{2}{*}{ Age (y) } & & \multicolumn{3}{|c|}{ Systolic (mm Hg) } & \multicolumn{3}{|c|}{ Diastolic $(\mathrm{mm} \mathbf{H g}$ ) } \\
\hline & & Rural & Urban & Difference (U-R) & Rural & Urban & Difference (U-R) \\
\hline \multirow[t]{3}{*}{$20-24$} & $\mathbf{n}$ & 28 & 63 & & 28 & 63 & \\
\hline & $\mathbf{m}$ & $120 \cdot 0$ & 122.6 & $2 \cdot 6$ & $67 \cdot 1$ & $63 \cdot 8$ & $-3 \cdot 3$ \\
\hline & SD & 13.7 & $12 \cdot 8$ & & 12.7 & $13 \cdot 1$ & \\
\hline \multirow[t]{3}{*}{$25-34$} & $\mathbf{n}$ & 78 & 78 & & 78 & 78 & \\
\hline & $\mathbf{m}$ & 122.9 & 122.6 & -0.3 & 68.6 & $69 \cdot 3$ & 0.7 \\
\hline & SD & $14 \cdot 0$ & $11 \cdot 2$ & & 13.4 & 10.9 & \\
\hline \multirow[t]{3}{*}{$35-44$} & $\mathbf{n}$ & 43 & 38 & & 43 & 38 & \\
\hline & $\mathbf{m}$ & $117 \cdot 7$ & $130 \cdot 3$ & $12 \cdot 6$ & $65 \cdot 3$ & $\mathbf{7 7 \cdot 0}$ & $11 \cdot 7$ \\
\hline & SD & $15 \cdot 8$ & 19.0 & & $13 \cdot 5$ & $14 \cdot 1$ & \\
\hline \multirow{3}{*}{$45-54$} & $\mathbf{n}$ & 33 & 25 & & 33 & 25 & \\
\hline & $\mathbf{m}$ & $121 \cdot 3$ & 129.9 & $8 \cdot 6$ & $71 \cdot 3$ & $76 \cdot 0$ & 4.7 \\
\hline & SD & $14 \cdot 2$ & $17 \cdot 8$ & & $11 \cdot 4$ & 13.9 & \\
\hline \multirow[t]{3}{*}{$55-64$} & $\mathbf{n}$ & 40 & 16 & & 40 & 16 & \\
\hline & $\mathbf{m}$ & 122.9 & 149.0 & $26 \cdot 1$ & 69.7 & $84 \cdot 4$ & $14 \cdot 7$ \\
\hline & SD & $16 \cdot 7$ & 21.4 & & $8 \cdot 3$ & $12 \cdot 5$ & \\
\hline \multirow[t]{3}{*}{$\geqslant 65$} & n & 42 & 0 & & 42 & 0 & \\
\hline & $\mathbf{m}$ & $129 \cdot 0$ & & & $67 \cdot 3$ & & \\
\hline & SD & $21 \cdot 3$ & & & $10 \cdot 5$ & & \\
\hline Annual increase ( $\mathrm{mm} \mathrm{Hg} / \mathrm{y})$ & & 0.14 & $0.56^{*}$ & & 0.02 & $0.54^{*}$ & \\
\hline
\end{tabular}

*Urban $v$ rural: $p<0.01$.

Table 2 Mean blood pressure by age in women

\begin{tabular}{|c|c|c|c|c|c|c|c|}
\hline \multirow[b]{2}{*}{ Age (y) } & & \multicolumn{3}{|c|}{ Systolic $(\mathrm{mm} \mathrm{Hg})$} & \multicolumn{3}{|c|}{ Diastolic $(\mathrm{mm} \mathbf{H g}$ ) } \\
\hline & & Rural & Urban & Difference (U-R) & Rural & Urban & Difference $(U-R)$ \\
\hline \multirow[t]{3}{*}{$20-24$} & $\mathbf{n}$ & 105 & 34 & & 105 & 34 & \\
\hline & m & $113 \cdot 1$ & 118.6 & $5 \cdot 5$ & $61 \cdot 4$ & $60 \cdot 5$ & -0.9 \\
\hline & SD & 11.6 & 11.0 & & $10 \cdot 0$ & 10.8 & \\
\hline \multirow{3}{*}{$25-34$} & $\mathbf{n}$ & 150 & 35 & & 150 & 35 & \\
\hline & $\mathrm{m}$ & 114.3 & 114.5 & $0 \cdot 2$ & $64 \cdot 7$ & 66.9 & $2 \cdot 2$ \\
\hline & SD & 12.4 & $11 \cdot 3$ & & $11 \cdot 8$ & $10 \cdot 5$ & \\
\hline \multirow[t]{3}{*}{$35-44$} & $\mathbf{n}$ & 139 & 14 & & 139 & 14 & \\
\hline & m & 116.0 & 119.8 & $3 \cdot 8$ & 66.6 & $69 \cdot 2$ & $2 \cdot 6$ \\
\hline & SD & 14.6 & 16.9 & & $10 \cdot 2$ & $9 \cdot 4$ & \\
\hline \multirow[t]{3}{*}{$45-54$} & n & 89 & 4 & & 89 & 4 & \\
\hline & $\mathbf{m}$ & 119.4 & 140.5 & $21 \cdot 1$ & $71 \cdot 0$ & $77 \cdot 5$ & $6 \cdot 5$ \\
\hline & SD & $20 \cdot 1$ & 29.2 & & $10 \cdot 3$ & 11.2 & \\
\hline \multirow[t]{3}{*}{$55-64$} & $\mathbf{n}$ & 62 & 2 & & 62 & 2 & \\
\hline & $\mathbf{m}$ & $129 \cdot 2$ & $138 \cdot 5$ & $9 \cdot 3$ & 72.5 & $82 \cdot 0$ & $9 \cdot 5$ \\
\hline & SD & $23 \cdot 2$ & 12.0 & & $11 \cdot 8$ & $4 \cdot 2$ & \\
\hline \multirow{3}{*}{$\geqslant 65$} & $\mathbf{n}$ & 52 & 1 & & 52 & 1 & \\
\hline & $\mathrm{m}$ & $136 \cdot 7$ & 144.0 & $7 \cdot 3$ & 69.9 & $79 \cdot 0$ & $9 \cdot 1$ \\
\hline & SD & $24 \cdot 8$ & - & & $13 \cdot 1$ & - & \\
\hline Annual increase $(\mathrm{mm} \mathrm{Hg} / \mathrm{y})$ & & 0.43 & $0.55^{*}$ & & 0.21 & $0.57^{*}$ & \\
\hline
\end{tabular}

*Urban $v$ rural: $\mathrm{p}<0.01$. 


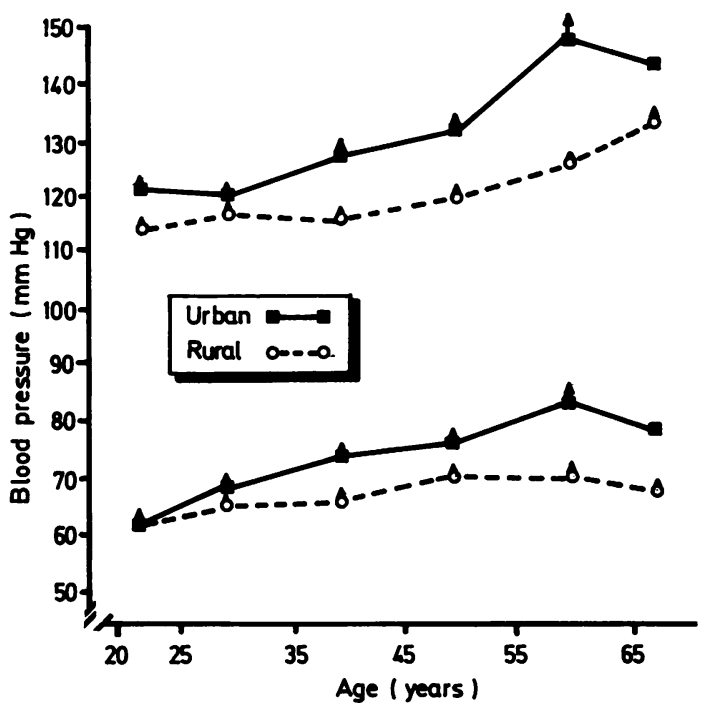

Mean systolic and diastolic blood pressures and their standard errors in urban and rural samples (men and women combined).

independent of age and vice versa, age having the bigger effect. Though mean weights were higher in the older urban groups, analysis of variance shows that weight differences did not account for all the differences between rural and urban blood pressures.

Women had greater skinfold thickness than men and urban values were greater than rural.

The relationships of blood pressure to body mass index and skinfold thickness were similar, but never stronger than those between blood pressure and body weight.

URINARY ELECTROLYTES AND RATIOS

Table 5 shows the mean values. The sodium/creatinine and potassium/creatinine ratios were normalised by logarithmic transformations. Relative to rural subjects the urban Luo had significantly higher mean urinary sodium concentration and sodium/potassium and sodium/creatinine ratios but significantly lower mean potassium concentration and potassium/creatinine ratios. Mean creatinine concentration did not differ significantly between the two groups. Within these urban and rural groups, blood pressures and urinary electrolyte ratios were not significantly correlated, except that in the urban Luo sodium concentration correlated significantly with systolic pressure $(\mathrm{r}=+0.18 ; \mathrm{p}<0.05)$.

URBAN RESIDENCE

Both systolic and diastolic pressures correlated

Table 3 Weight, body mass index (BMI), and triceps skinfold thickness (SFT) by age in men

\begin{tabular}{|c|c|c|c|c|c|c|}
\hline \multirow[b]{2}{*}{ Age (y) } & \multicolumn{3}{|l|}{ Rural } & \multicolumn{3}{|l|}{ Urban } \\
\hline & Weight (kg) (sd) & $B M I\left(\mathrm{~kg} / \mathrm{m}^{2}\right)(\mathrm{sd})$ & $S F T(\mathrm{~mm})(\mathrm{sd})$ & Weight (kg) (sd) & $B M I\left(\mathrm{~kg} / \mathrm{m}^{2}\right)(\mathrm{sd})$ & $S F T(\mathrm{~mm})(\mathrm{sd})$ \\
\hline $20-24$ & $\begin{array}{c}60 \cdot 0 \\
(7 \cdot 3)\end{array}$ & $\begin{array}{c}20.1 \\
(1.9)\end{array}$ & $\begin{array}{c}6.7 \\
(3.0)\end{array}$ & $\begin{array}{c}59.7 \\
(6.6)\end{array}$ & $\begin{array}{c}19.5 \\
(1.6)\end{array}$ & $\begin{array}{c}6.1 \\
(1.6)\end{array}$ \\
\hline $25-34$ & $\begin{array}{l}61 \cdot 2 \\
(10 \cdot 8)\end{array}$ & $\begin{array}{c}21.0 \\
(4 \cdot 5)\end{array}$ & $\begin{array}{c}6 \cdot 5 \\
(2 \cdot 4)\end{array}$ & $\begin{array}{c}61.4 \\
(7.9)\end{array}$ & $\begin{array}{c}20 \cdot 3 \\
(2 \cdot 1)\end{array}$ & $\begin{array}{c}7 \cdot 3 \\
(5 \cdot 3)\end{array}$ \\
\hline $35-44$ & $\begin{array}{c}60.4 \\
(9.4)\end{array}$ & $\begin{array}{c}20 \cdot 1 \\
(2 \cdot 6)\end{array}$ & $\begin{array}{c}6 \cdot 2 \\
(2 \cdot 9)\end{array}$ & $\begin{array}{c}64.7 \\
(10.9)\end{array}$ & $\begin{array}{c}21.6 \\
(3.4)\end{array}$ & $\begin{array}{l}9 \cdot 0 \\
(5 \cdot 2)\end{array}$ \\
\hline $45-54$ & $\begin{array}{c}58.7 \\
(8.5)\end{array}$ & $\begin{array}{c}20.2 \\
(2 \cdot 7)\end{array}$ & $\begin{array}{c}5 \cdot 6 \\
(1.6)\end{array}$ & $\begin{array}{c}63 \cdot 1 \\
(10 \cdot 2)\end{array}$ & $\begin{array}{c}20.9 \\
(3 \cdot 1)\end{array}$ & $\begin{array}{c}8 \cdot 2 \\
(4 \cdot 5)\end{array}$ \\
\hline $55-64$ & $\begin{array}{c}58.5 \\
(9.4)\end{array}$ & $\begin{array}{c}19.9 \\
(2.0)\end{array}$ & $\begin{array}{c}6 \cdot 6 \\
(2 \cdot 5)\end{array}$ & $\begin{array}{c}64 \cdot 2 \\
(10 \cdot 6)\end{array}$ & $\begin{array}{c}21 \cdot 1 \\
(3 \cdot 2)\end{array}$ & $\begin{array}{c}8 \cdot 6 \\
(4 \cdot 0)\end{array}$ \\
\hline$\geqslant 65$ & $\begin{array}{c}53 \cdot 1 \\
(8 \cdot 5)\end{array}$ & $\begin{array}{c}19 \cdot 3 \\
(2 \cdot 2)\end{array}$ & $\begin{array}{c}6 \cdot 4 \\
(2 \cdot 1)\end{array}$ & & & \\
\hline
\end{tabular}

Table 4 Weight, body mass index (BMI), and triceps skinfold thickness (SFT) by age in women

\begin{tabular}{|c|c|c|c|c|c|c|}
\hline \multirow[b]{2}{*}{ Age (y) } & \multicolumn{3}{|l|}{ Rural } & \multicolumn{3}{|l|}{ Urban } \\
\hline & Weight (kg) (sd) & $B M I\left(k g / m^{2}\right)(s d)$ & $S F T(m m)(s d)$ & Weight $(k g)(s d)$ & $B M I\left(k g / m^{2}\right)(s d)$ & $S F T(m m)(s d)$ \\
\hline $20-24$ & $\begin{array}{l}55.6 \\
(6.9)\end{array}$ & $\begin{array}{l}21 \cdot 5 \\
(2 \cdot 6)\end{array}$ & $\begin{array}{c}13 \cdot 8 \\
(5 \cdot 1)\end{array}$ & $\begin{array}{c}55.8 \\
(6.9)\end{array}$ & $\begin{array}{c}21 \cdot 1 \\
(2 \cdot 0)\end{array}$ & 14.6 \\
\hline $25-34$ & $\begin{array}{c}54 \cdot 3 \\
(8 \cdot 8)\end{array}$ & $\begin{array}{l}20.8 \\
(2.9)\end{array}$ & $\begin{array}{l}12 \cdot 8 \\
(4 \cdot 9)\end{array}$ & $\begin{array}{c}62.4 \\
(13.0)\end{array}$ & $\begin{array}{l}22 \cdot 8 \\
(3 \cdot 8)\end{array}$ & $\begin{array}{l}(5.3) \\
(10.7\end{array}$ \\
\hline $35-44$ & $\begin{array}{c}53.8 \\
(8.9)\end{array}$ & $\begin{array}{l}20.6 \\
(3.6)\end{array}$ & $\begin{array}{l}12 \cdot 6 \\
(5 \cdot 6)\end{array}$ & $\begin{array}{c}62 \cdot 5 \\
(11 \cdot 1)\end{array}$ & $\begin{array}{l}22.9 \\
(4.0)\end{array}$ & $\begin{array}{c}25.4 \\
(13.5)\end{array}$ \\
\hline $45-54$ & $\begin{array}{l}51 \cdot 1 \\
(9.6)\end{array}$ & $\begin{array}{l}19.7 \\
(3.3)\end{array}$ & $\begin{array}{l}11.9 \\
(5 \cdot 8)\end{array}$ & $\begin{array}{c}66.5 \\
(11 \cdot 2)\end{array}$ & $\begin{array}{c}23.4 \\
(4.0)\end{array}$ & $\begin{array}{l}23 \cdot 7 \\
(4 \cdot 3)\end{array}$ \\
\hline $\begin{array}{l}55-64 \\
\geqslant 65\end{array}$ & $\begin{array}{c}47 \cdot 5 \\
(7 \cdot 0) \\
45 \cdot 1 \\
(7 \cdot 5)\end{array}$ & $\begin{array}{c}18 \cdot 6 \\
(2 \cdot 5) \\
18 \cdot 1 \\
(2 \cdot 4)\end{array}$ & $\begin{array}{c}9 \cdot 4 \\
(4 \cdot 3) \\
8 \cdot 5 \\
(3 \cdot 1)\end{array}$ & $\begin{array}{c}48 \cdot 5 \\
(2 \cdot 1) \\
59 \cdot 0 \\
(-)\end{array}$ & $\begin{array}{c}17 \cdot 4 \\
(2 \cdot 1) \\
25 \cdot 5 \\
(-)\end{array}$ & $\begin{array}{c}10 \cdot 1 \\
(0 \cdot 1) \\
25 \cdot 4 \\
(-)\end{array}$ \\
\hline
\end{tabular}


Table 5 Electrolyte and creatinine concentrations and ratios in casual urine samples

\begin{tabular}{|c|c|c|}
\hline & Rural & Urban \\
\hline & Mean (sd) & Mean (sd) \\
\hline $\mathrm{Na}(\mathrm{mmol} / \mathrm{l})$ & $\begin{array}{c}82.4 \\
(54 \cdot 7)\end{array}$ & $\begin{array}{r}108 \cdot 6^{*} \\
(61 \cdot 2)\end{array}$ \\
\hline K (mmol/l) & $\begin{array}{c}67.4 \\
(46.4)\end{array}$ & $\begin{array}{r}38.4^{*} \\
(28.8)\end{array}$ \\
\hline Creatinine (mmol/l) & $\begin{array}{c}11 \cdot 5 \\
(7.4)\end{array}$ & $\begin{array}{c}10.6 \\
(6.6)\end{array}$ \\
\hline $\mathrm{Na} / \mathrm{K}$ & $\begin{array}{c}1.7 \\
(1.6)\end{array}$ & $\begin{array}{c}4 \cdot 2^{*} \\
(3.4)\end{array}$ \\
\hline $\mathrm{Na}$ /creatinine & $\begin{array}{c}12.5 \\
(39.8)\end{array}$ & $\begin{array}{l}13.6 \\
(11.5)\end{array}$ \\
\hline Log $\mathrm{Na} /$ creatinine & $\begin{array}{c}0.85 \\
(0.40)\end{array}$ & $\begin{array}{r}1.03^{*} \\
(0.31)\end{array}$ \\
\hline $\mathrm{K} /$ creatinine & $\begin{array}{c}11 \cdot 1 \\
(56 \cdot 2)\end{array}$ & $\begin{array}{c}4 \cdot 2^{*} \\
(5 \cdot 4)\end{array}$ \\
\hline Log $K /$ creatinine & $\begin{array}{c}0.76 \\
(0.40)\end{array}$ & $\begin{array}{c}0.52^{*} \\
(0.26)\end{array}$ \\
\hline
\end{tabular}

* Rural $v$ urban $\mathrm{p}<0.001$.

significantly with duration of urban residence. Duration of urban residence also correlated with age; after age adjustment, the partial correlation was still significant for systolic pressure $(r=+0 \cdot 11$; $\mathrm{p}<0.005)$ but not diastolic $(\mathrm{r}=+0.06)$.

\section{OTHER FACTORS}

The proportion of smokers was similar in the urban and rural groups (25\% and $28 \%$ respectively); but $42 \%$ of the urban compared with $23 \%$ of the rural population reported drinking alcohol at least once a week and $12 \%$ of the urban compared with $1 \%$ of the rural group admitted to heavy drinking $(>40 \mathrm{~g}$ alcohol a day). In an analysis of variance taking into account the effects of age, weight, and sex, however, there was no apparent association between blood pressure and reported smoking or alcohol consumption.

In both urban and rural groups blood pressure in women increased with parity, but the effect was not significant after taking account of age and weight.

Albuminuria was found in $5 \cdot 8 \%$ (rural) and $4 \cdot 2 \%$ (urban), glycosuria in $0.2 \%$ (rural) and $0.6 \%$ (urban), and chemical haematuria in $4.6 \%$ (rural) and $3.6 \%$ (urban). There was no evident relation between blood pressure and these findings and urban/rural differences were not significant.

Ambient temperature was not significantly related to blood pressure and there was no significant urban/rural difference.

\section{Discussion}

Hypertension and its sequelae are a major and probably increasing cause of morbidity and mortality among Africans. ${ }^{12}$ Several communities in Kenya have been described in which mean blood pressures have been low and showed little or no rise with age and essential hypertension was rare or non-existent. ${ }^{1-3}$ These have been loosely defined nomadic or hunter gatherer groups. The rural men reported here seem to be the first agricultural population whose diastolic pressures do not rise significantly with age.

The rural part of this study was undertaken in a stable agricultural community recruiting subjects randomly from a recent population census. Mean blood pressures were low, and in men they rose little with age (apart from an increase of systolic in the oldest age group). Since it was not possible to identify Luo in Nairobi using a population census, the urban group was recruited by contact tracing. Their strong sense of tribal identity ensured that the sample was broad based, however, and the response among identified subjects was $100 \%$. The highly significant differences in blood pressures between rural and urban Luo are probably not due to measurement technique, which was carefully standardised, nor to selection bias, which could hardly produce the different regression slopes of blood pressure with age seen in the urban and rural groups.

The similarity between the urban and rural pressures of those aged 20-34 may in part be explained by the correlation between duration of urbanisation and age, since many of the younger individuals had been in Nairobi for only a few months. Although alcohol intake was significantly higher in the urban group, we were unable to confirm the finding reported elsewhere of an association with blood pressure. ${ }^{13}$

There is much evidence that dietary electrolytes influence blood pressure. ${ }^{1415}$ Sodium intake is generally considered to be low in the primitive "low blood pressure" societies, ${ }^{16}$ although few data are available from African studies to support this hypothesis. In westernised societies where hypertension is a problem, sodium intake is variable but in excess of requirements, ${ }^{17}$ and the mean sodium intake of populations has been correlated with their mean blood pressure levels. ${ }^{18}$ More recently, the role of potassium in protecting against the effect of high sodium intake has emerged from animal and clinical studies, ${ }^{19-21}$ and one population study ${ }^{22}$ has shown a negative correlation in individuals between urinary potassium and blood pressure. Urban and rural Luo showed highly significant differences in their urinary electrolyte patterns, implying different dietary intakes of sodium and potassium.

There has been much criticism of the use of casual urine samples as estimates of overall urinary electrolyte excretion and, by inference, dietary electrolyte content ${ }^{23}$ In this study the aim was merely to provide information on overall differences in 
electrolyte excretion in two populations, which we believe is justifiable.

Conclusions on the validity of casual urine samples based on studies in westernised societies, where day to day intraindividual variations in urinary electrolyte excretions are high and are greater than intersubject variations, ${ }^{24}$ cannot necessarily be extrapolated to studies in more primitive societies where individual diets are more stable. For example, in these communities we have shown much less variability in electrolyte excretion within individual subjects than between subjects. ${ }^{25}$ Moreover, casual urine sodium/potassium ratios in these groups correlate highly with values obtained from total seven day urine collections. ${ }^{25}$

In the rural samples the mean sodium concentrations and sodium/creatinine ratios were much lower than those found in westernised populations, ${ }^{75}$ and since their mean 24 hour urine volumes were about $1100 \mathrm{ml}$ (N Poulter, unpublished data), the average urinary sodium excretion would be in the region of $90 \mathrm{mmol} / \mathrm{day}$. Thus our findings are in keeping with Page's statement that all populations with low blood pressure have a low dietary salt intake. ${ }^{16}$ In the present study, however, potassium excretion showed urban/rural differences that were as large and as significant as those for sodium, but in the reverse direction.

This study confirms that populations of the same genetic origin may have different blood pressure patterns in different environments. The observed difference between these two groups could be related to differences in intake of sodium or potassium, or in the ratio of the two. Nevertheless, more definitive data on all the various dietary changes that the rural Luo make on migration to Nairobi will subsequently be available from the longitudinal study presently in progress.

K T Khaw is a Wellcome Trust Research Fellow. This study was supported by the Wellcome Trust.

\section{References}

${ }^{1}$ Donnison CP. Blood pressure in the African native. Lancet 1929; i: 6-7.

${ }^{2}$ Shaper AG, Williams AW, Spencer P. Blood pressure and body build in an African tribe living on a diet of milk and meat. $E$ A fr Med J 1961; 38: 569-80.

${ }^{3}$ Shaper AG, Wright DH, Kyobe J. Blood pressure and body build in three nomadic tribes of northern Kenya. $E$ Afr Med J 1969; 46: 273-81.
${ }^{4}$ Truswell AS, Kennelly BM, Hansen JDL, Lee RB. Blood pressures of Kung bushmen in Northern Botswana. Am Heart J 1972; 84: 5-12.

${ }^{5}$ Mann GV, Roels AA, Price DL, Merrill JM. Cardiovascular disease in African pygmies. $J$ Chronic Dis 1962; 15: 341-71.

${ }^{6}$ Mann GV, Shaffer RD, Anderson RS, Sandstead HH. Cardiovascular disease in the Masai. J Atherosclerosis Res 1964; 4: 289-312.

${ }^{7}$ Sever PS, Gordon D, Peart WS, Beighton P. Blood pressure and its correlates in urban and tribal Africa. Lancet 1980; ii: 60-4.

${ }^{8}$ Shaper AG, Leonard PJ, Jones $\mathbf{K W}$, Jones $\mathbf{M}$. Environmental effects on the body build, blood pressure and blood chemistry of nomadic warriors serving in the army in Kenya. E Afr Med J 1969; 46: 282-9.

${ }^{9}$ Wright BM, Dore F. A random-zero sphygmomanometer. Lancet 1970; i: 337-8.

${ }^{10}$ Rose G. Standardisation in blood pressure measurement. Lancet 1965; i: 673-4.

${ }^{11}$ Rose G, Blackburn H. Cardiovascular survey methods. Geneva: World Health Organisation, 1968; (Monograph series).

${ }^{12}$ Akinkugbe OO. High blood pressure in the African. Edinburgh: Churchill-Livingstone, 1972.

${ }^{13}$ Klatsky AL, Friedman GD, Siegelaub AB, Gerard MJ. Alcohol consumption and blood pressure. Kaiser-permanente multiphasic health examination data. $N$ Engl J Med 1977; 296: 1194-200.

${ }^{14}$ De Wardener HE, Macgregor GA. Dahl's hypothesis that a saluretic substance may be responsible for a sustained rise in arterial pressure: its possible role in essential hypertension. Kidney Int 1980; 18: 1-9.

${ }^{15}$ Dahl LK. Salt and hypertension. Am J Clin Nutr 1972; 25: 231-44.

${ }^{16}$ Page LB. Epidemiologic evidence on the etiology of human hypertension and its possible prevention. $\mathrm{Am}$ Heart J 1976; 91: 527-34.

${ }^{17}$ Dahl LK. Salt intake and salt need. $N$ Engl J Med 1958; 258: 1152-7.

${ }^{18}$ Gleiberman L. Blood pressure and dietary salt in human populations. Ecology of Food and Nutrition 1973; 2: 143-56.

${ }^{19}$ Meneely GR, Battarbee HD. High sodium and low potassium environment and hypertension. Am J Cardiol 1976; 38: 768-85.

${ }^{20}$ Young DB, McCaa RE, Yi-Jens MS, Guyton AC. The natriuretic and hypotensive effects of potassium. Circ Res 1976; 38, suppl 2: 84-9.

${ }^{21}$ Lever AF, Beretta-Piccoli B, Brown JJ, Davies DL, Fraser R, Robertson JIS. Sodium and potassium in essential hypertension. $\mathrm{Br}$ Med J 1981; 283: 463-8.

${ }^{22}$ Khaw KT, Rose G. Population study of blood pressure and associated factors in St Lucia, West Indies. Int J Epidemiol (in press.)

${ }^{23}$ Cummins RO, Shaper AG, Walker M. Methodological problems with estimation of salt intake. Lancet 1981; i: 1373-4.

${ }^{24}$ Liu K, Cooper R, McKeever J, et al. Assessment of the association between habitual salt intake and high blood pressure: methodological problems. Am J Epidemiol 1979; 110: 219-26.

${ }^{25}$ Poulter N, Khaw, KT, Hopwood BEC, et al. Blood pressure and associated factors in a rural Kenyan community. Hypertension (in press). 